\title{
Blood clotting factors in cerebrospinal fluid
}

\author{
STEFAN NIEWIAROWSKI ${ }^{1}$, IRENA HAUSMANOWA-PETRUSEWICZ, AND \\ ZENON WEGRZYNOWICZ ${ }^{2}$
}

From the Department of Neurology, the Medical School, Warsaw, Poland

SYNOPSIS The activity of blood clotting factors has been investigated in cerebrospinal fluid. No cephalin-like activity was found in cerebrospinal fluid but prothrombin activity averaged about $0.5 \%$ of normal plasma activity. The activity of factor VII was negligible in almost all cases. The activity of antihaemophilic factors showed great variation but in the majority of cases it did not exceed $1 \%$ of normal plasma activity. High activity for factor $\mathrm{V}$ was found in almost all samples of cerebrospinal fluid.

Many papers have been published on the electrophoretic pattern of the proteins and on enzymes in cerebrospinal fluid but the activity of blood-clotting factors in cerebrospinal fluid has not been sufficiently investigated. The presence of substances accelerating the coagulation of normal human plasma in cerebrospinal fluid has been demonstrated by Kafka (1945, 1950, 1955), and, according to Putnam (1937), the basic abnormality of multiple sclerosis is to be found in disturbances of the clotting mechanisms. Persson (1956) discovered a platelet-agglutinating substance in the cerebrospinal fluid in multiple sclerosis and in cerebral syphilis only, a fact which Feldman, Izak, and Nelken (1957) could not confirm. Albright, Kupfer, and Kinne (1959) found that neither normal spinal fluid nor that of multiple sclerosis patients had any thromboplastic activity in blood or tissue. Nour-Eldin (1959) considers cerebrospinal fluid to be inactive in the clotting processes although Kundu and Chaterjea (1961) showed the existence of an active substance in the thromboplastin generation test in cerebrospinal fluid. Antithrombic activity of normal and pathological cerebrospinal fluid was recently discovered by Gaertner, Lisiewicz, and Caen (1961).

The purpose of this paper is to examine the activity of the clotting factors in cerebrospinal fluid in various patients. The activity of factor $\mathrm{V}$ was surprisingly high in almost all samples tested.

\footnotetext{
${ }^{1}$ Present address: Department of Physiological Chemistry, Medical School, Bialystok, Poland.

'Present address: Department of Health Protection, Institute of Nuclear Research, Warsaw-Żeran, Poland.
}

Received for publication 22 March 1962.

\section{CLINICAL MATERIAL}

Fresh cerebrospinal fluid from 68 patients in the Neurological Department was collected by lumbar puncture. The interval between lumbar puncture and laboratory investigations never exceeded three hours. In 10 patients no neurological abnormalities were found, and samples of cerebrospinal fluid taken from them were considered normal. Of the remaining patients, 16 had suffered a cerebral haemorrhage, 10 had encephalitis, six had primary tumours of the brain or spinal cord, four had epilepsy, five had disseminated sclerosis, three had muscular dystrophy, and seven had various inflammatory diseases of the central or peripheral nervous system. Each of the remaining seven patients was suffering from a different disease of the central nervous system. All samples of the investigated cerebrospinal fluid showed normal protein levels (33 to $39 \mathrm{mg}$.\%). Samples containing blood were not tested.

Plasma from patients with congenital haemorrhagic diseases was supplied by Dr. H. Cetnarowicz.

\section{METHODS}

The clotting factors in cerebrospinal fluid were determined using one-stage methods, and its cephalin-like activity was tested by two reagents. First $0.2 \mathrm{ml}$. human citrated platelet-poor plasma $+0.1 \mathrm{ml}$. cerebrospinal fluid (or saline) $+0.05 \mathrm{ml} .0 .1 \mathrm{M} \mathrm{CaCl}_{2}$. and secondly, $0.05 \mathrm{ml}$. cerebrospinal fluid or saline or cephalin + $0.05 \mathrm{ml}$. Russell viper venom 1:10.000 (Stypven) + $0.2 \mathrm{ml}$. human citrated platelet-poor plasma $+0.05 \mathrm{ml}$. $0 \cdot 1 \mathrm{M} \mathrm{CaCl}_{2}$. Cephalin was obtained by the method of Bell and Alton (1954).

'True' prothrombin was estimated by the method of Soulier and Larrieu (1952), factor $V$ by the method of Wolf (1953), and factor VII by the method of Koller, Loeliger, and Duckert (1951). The reagent used was $0.1 \mathrm{ml}$. of 'substrate' plasma $+0.1 \mathrm{ml}$. cerebrospinal 
fluid or saline or diluted human plasma $+0 \cdot 1 \mathrm{ml}$. rabbit brain thromboplastin $+0.1 \mathrm{ml}$. calcium chloride $0.025 \mathrm{M}$. Usually substrate plasma was prepared artificially but in some instances plasma from patients with congenital factor V and factor VII deficiency was used.

Antihaemophilic globulin (factor VIII), Christmas factor (factor IX), plasma thromboplastin antecedent (factor XI), and Hageman factor (factor XII) were tested by the slightly modified method of Soulier and Larrieu (1953). The reagents were 'substrate' plasma, made up of $0.1 \mathrm{ml} .+\mathbf{0 . 1} \mathrm{ml}$. cerebrospinal fluid or saline or diluted human plasma $+0.1 \mathrm{ml}$. 0.025 $\mathrm{M}$ calcium chloride. The plasma of patients with haemophilia A, haemophilia B, and 'exhausted' plasma, that is, plasma derived artificially from Hageman factor and plasma thromboplastin antecedent (Waaler, 1959), were used as substrate plasmas.

For every set of determinations standard dilution curves of blood clotting factors contained in fresh human citrated plasma were made, and the activity of each clotting factor in human plasma was designated as $100 \%$. Clotting activities of cerebrospinal fluid were expressed in volume per cent of the normal plasma activity. These values were calculated from the standard dilutions curve by interpolation.

\section{RESULTS}

Preliminary experiments with 22 samples of cerebrospinal fluid (Table I) demonstrated that all fluids were devoid of any cephalin-like activity when tested by both methods.

TABLE I

LACK OF CEPHALIN-LIKE ACTIVITY IN CEREBROSPINAL FLUID

\begin{tabular}{lll} 
Sample & \multicolumn{2}{l}{ Clotting Time (sec.) } \\
\cline { 2 - 3 } & Method 1 & Method 2 \\
\hline Saline (control) & 160 & 20 \\
Cerebrospinal fluid mean values & & \\
from 22 samples & $154 \cdot 2 \pm 11 \cdot 2$ & $19 \cdot 1 \pm 2 \cdot 61$ \\
Cephalin $1: 1,000$ & 101 & 8 \\
Cephalin $1: 10,000$ & 113 & 10 \\
Cephalin $1: 50,000$ & 120 & 17
\end{tabular}

The results of determinations of blood clotting factors in 52 samples of cerebrospinal fluid obtained from various patients are shown in Table II. The concentration of protein in plasma is about 200 times higher than in cerebrospinal fluid and prothrombin activity averaged about $0.5 \%$ of normal plasma activity. Thus, if expressed per milligram of protein, the activity of prothrombin in cerebrospinal fluid was almost the same as in plasma. A high activity of factor $\mathrm{V}$ in cerebrospinal fluid was found in 49 cases; in $55 \%$ of cases it exceeded $5 \%$ of the normal plasma activity and in $30 \%$ of cases $10 \%$. The activity of factor $\mathrm{V}$ in the fluid of patient J.W., recovering from tubercular meningitis, attained $75 \%$ of plasma activity. Factor $\mathrm{V}$ was 150 times per milligram protein more active in cerebrospinal fluid than in plasma, and in other fluids more than 10 times more than in plasma. The activity of factor $\mathrm{V}$ in the control group fluids was as follows:-In six cases it fluctuated from 2 to $5 \%$ of the normal plasma activity, in two cases from 5 to $10 \%$, and in two cases it exceeded $10 \%$. The activity of the different disease processes and of factor $\mathrm{V}$ could not be correlated precisely because the number of investigated patients was too small. The cerebrospinal fluid of patients with epilepsy and certain inflammatory conditions seemed to show a particularly high activity of factor V but that of factor VII was negligible in almost all cases. If calculated per millilitre of fluid it was negligible in almost all cases but if calculated per milligram of protein it was considerably lower in cerebrospinal fluid than in plasma. Similar results were obtained when instead of bovine Seitz-filtered plasma that of a patient with congenital factor VII deficiency was used in the experiments. The activity of antihaemophilic factors in cerebrospinal fluid showed great variation. In most of the pathological and in all normal fluids, however, it did not exceed $1 \%$ of normal plasma activity.

The high factor $\mathrm{V}$ activity in cerebrospinal fluid seemed to be the most interesting finding, so we tried to compare the influence of cerebrospinal fluid upon the prothrombin time of plasma artificially deprived of factor $\mathrm{V}$ activity $\left(24\right.$ hours' incubation at $37^{\circ} \mathrm{C}$.) and upon the plasma of a patient with congenital factor $\mathrm{V}$ deficiency. As seen in Fig. 1, the addition of cerebrospinal fluid similarly made the prothrombin time of both plasmas normal.

TABLE II

BLOOD CLOTTING FACTORS IN CEREBROSPINAL FLUID

Clotting Factor

Number of Samples

Clotting Activity of Cerebrospinal Fluid (Vol. \% of Activity of Normal Plasma)

\begin{tabular}{llllllll}
\hline$<0.1$ & $0 \cdot 1-0.5$ & $0.5-1.0$ & $1 \cdot 0-2 \cdot 0$ & $2 \cdot 0-5 \cdot 0$ & $5 \cdot 0-10 \cdot 0$ & $10 \cdot 0$ & Total
\end{tabular}

Prothrombin

Factor V

Factor VII complex

Factor VIII

Factor IX

Factor XI + Hageman factor

32
1
27
26
20
12

$\begin{array}{rrrrrr}10 & 3 & - & - & - & 51 \\ 1 & 4 & 28 & 16 & 18 & 68 \\ 2 & - & - & - & - & 52 \\ 3 & 6 & 3 & 1 & - & 52 \\ 6 & 6 & 8 & 1 & 1 & 52 \\ 5 & 36\end{array}$




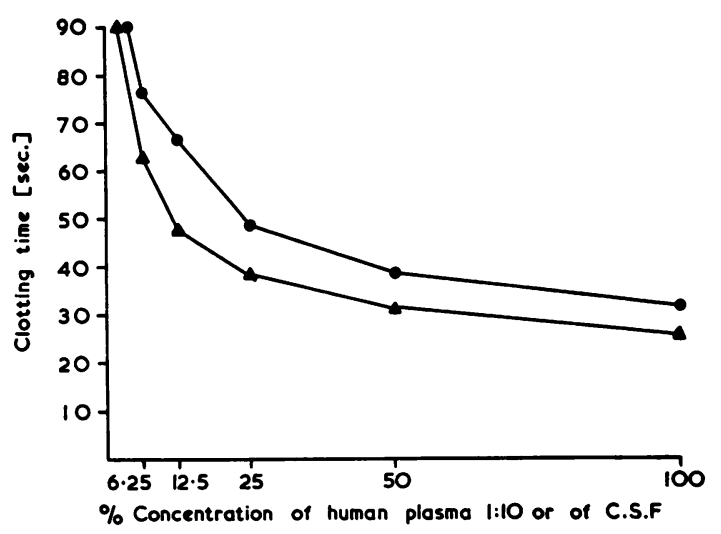

FIG. 1a

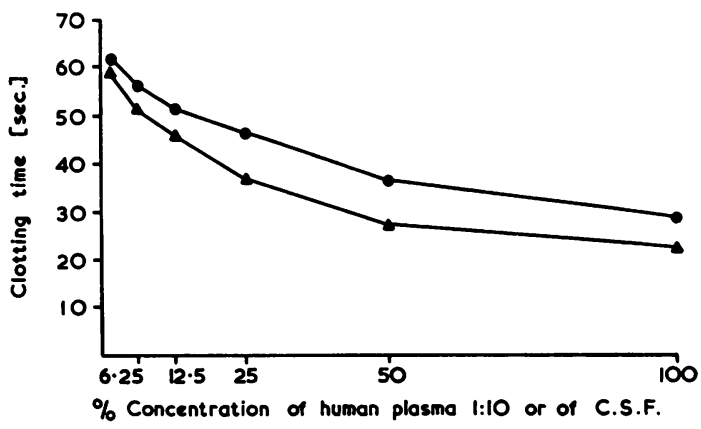

FIG. $1 \mathrm{~b}$

FIGS. 1a and 1b. Influence of human plasma or cerebrospinal fluid on the prothrombin time of plasma artificially deprived of factor $V$ (Fig. Ia) and on the prothrombin time of plasma from a case of congenital factor $V$ deficiency (Fig. 1b).

TABLE III

INFLUENCE OF STORAGE ON FACTOR $V$ ACTIVITY ${ }^{1}$ IN CEREBROSPINAL FLUID

\begin{tabular}{|c|c|c|c|c|}
\hline \multirow{2}{*}{$\begin{array}{l}\text { Sample of } \\
\text { Cerebrospinal } \\
\text { Fluid }\end{array}$} & \multicolumn{4}{|c|}{ Clotting Time (sec.) } \\
\hline & $\begin{array}{l}\text { Fresh } \\
\text { Sample }\end{array}$ & $\begin{array}{l}\text { Stored } \\
24 \text { Hours } \\
+24^{\circ} \mathrm{C} .\end{array}$ & $\begin{array}{l}\text { Stored } \\
24 \text { Hours } \\
+4^{\circ} \mathrm{C}\end{array}$ & $\begin{array}{l}\text { Stored } \\
24 \text { Hours } \\
-20^{\circ} \mathrm{C} .\end{array}$ \\
\hline 1 & 26 & 82 & 36 & 39 \\
\hline 2 & 30 & 135 & 108 & 45 \\
\hline 3 & 30 & 130 & 85 & 37 \\
\hline 4 & 47 & 142 & 140 & 83 \\
\hline 5 & 39 & 110 & 80 & 54 \\
\hline 6 & 43 & 125 & 100 & 57 \\
\hline 7 & 30 & 110 & 90 & 38 \\
\hline \multicolumn{5}{|l|}{ Human plasma } \\
\hline diluted $1: 10$ & 25 & 50 & 33 & 30 \\
\hline Saline control & 130 & - & - & - \\
\hline
\end{tabular}

${ }^{1}$ Tested on human plasma incubated for 24 hours at $37^{\circ} \mathrm{C}$.
Factor $\mathrm{V}$ in cerebrospinal fluid is extremely labile; it becomes inactivated at room temperature, at $+4^{\circ} \mathrm{C}$., and after freezing and thawing (Table III).

\section{DISCUSSION}

The above experiments permit us to conclude that the patterns of clotting factors in blood plasma and cerebrospinal fluid are entirely different. The activity of prothrombin in cerebrospinal fluid calculated per milligram of protein is of the same order as in plasma. It is possible, however, that factor VII is retained by the blood-fluid barrier, as its activity per milligram of protein is considerably lower in cerebrospinal fluid than in plasma. In the majority of cases only a trace of factor VII was found. As, however, methods used in this study do not record minute amounts of the clotting factors, it is difficult to decide whether the trace activity of factor VII found in some samples of cerebrospinal fluid was connected with the presence of true factor VII or is due to some nonspecific effect.

It is not possible to decide whether the activity of factor $\mathrm{V}$ in cerebrospinal fluid is dependent upon the same protein as in blood plasma. If so, our experiments suggest that factor $\mathrm{V}$ is concentrated in cerebrospinal fluid, a fact which is difficult to explain on the basis of present experimental data. It should be emphasized that factor $\mathrm{V}$ activity is not raised in other biological fluids. Yatzidis and Richet (1957) ascertained a lack of factor $\mathrm{V}$ in urine, and, according to Nour-Eldin (1959), ascitic fluid and pleural effusion contain factor $\mathrm{V}$ in low concentrations only. Hansen and Aepinus (1960) showed that the activity of this factor in the lymph was lower than in blood plasma but the patterns of the clotting factors in blood plasma and in lymph were similar.

Significant variations in factor $\mathrm{V}$ and antihaemophilic factors in cerebrospinal fluid might be due to several factors. The extreme lability of the clotting factors in a solution of a low-protein concentration is well known as also is the fact that some clotting factors are inactivated by proteolytic enzymes (Alagille and Soulier, 1956; Niewiarowski and Latallo, 1957). The active proteolytic enzyme in cerebrospinal fluid occurs in various diseases, especially in cerebrovascular disease, headache, and migraine (Chapman and Wolff, 1958). Moreover, all other factors influencing the permeability of the blood-fluid barrier, e.g., chemical and physical changes in the blood, diseases of the meninges and of the central nervous system, changed permeability of the vessels of the barrier, might also affect the concentration of the clotting factors in cerebrospinal fluid (Lups and Haan, 1954). 


\section{REFERENCES}

Alagille, D., and Soulier, J. P. (1956). Sem. Hôp. Paris, 32, 355. Albright, S. D., Kupfer, H. G., and Kinne, D. R. (1959). Arch. Neurol. (Chic.), 1, 315 .

Bell, W. N., and Alton, H. G. (1954). Nature, Lond., 174, 880.

Chapman, L. F., and Wolff, H. G. (1958). Trans. Ass. Amer. Phycns., $71,210$.

Feldman, S., Izak, G., and Nelken, D. (1957). Acta psychiat. scand., $32,37$.

Gaertner, H. A., Lisiewicz, J., and Caen, J. (1961). Nature, Lond., $192,1164$.

Hansen, H. G., and Aepinus, K. (1960). Thrombos. Diathes. haemorrh. (Stuttg.), 4, 435.

Kafka, V. (1945). Acta med. scand., 120, 147. (1950). Acta psychiat. (Kbh.). 25, 67.

- (1955). Nervenarzt, 26, 166.

Koller, F., Loeliger, A., and Duckert, F. (1951). Acta haemat. (Basel), $6,1$.
Kundu, H. B., and Chaterjea, J. B. (1961). Bull. Calcutta Sch. trop. Med., 9, 57.

Lups, S., and Haan, A. (1954). The Cerebrospinal Fluid. Elsevier, Amsterdam.

Niewiarowski, S., and Latallo, Z. (1957). Bull. Acad. pol. Sci. Cl. 2, $5,219$.

Nour-Eldin, F. (1959). Proc. IVth International Congress of Biochemistry Vienna 1958, Vol. 10, p. 138. Pergamon Press, London.

Persson, I. (1956). A.M.A. Arch. Neurol. Psychiat., 76, 343.

Putnam, T. J. (1937). Ibid., 37, 1298.

Soulier, J. P., and Larrieu, M. J. (1952). Sang, 23, 549. (1953). Ibid., 24, 205.

Yatzidis, H., and Richet, G. (1957). Rev. franc. Etud. clin. biol., 2, 717.

Waaler, B. A. (1959). Contact Activation in the Intrinsic Blood Clotting System, Scand. J. clin. Lab. Invest., 11, Suppl. 37. Wolf, P. (1953). J. clin. Path., 6, 34. 